University of Nebraska - Lincoln

DigitalCommons@University of Nebraska - Lincoln

Faculty Publications, Department of Psychology

Psychology, Department of

2009

\title{
How Should the Effectiveness of the EPPP Be Judged?
}

David DiLillo

University of Nebraska-Lincoln, ddilillo@unl.edu

George C. Tremblay

Antioch University

Follow this and additional works at: https://digitalcommons.unl.edu/psychfacpub

Part of the Psychiatry and Psychology Commons

DiLillo, David and Tremblay, George C., "How Should the Effectiveness of the EPPP Be Judged?" (2009).

Faculty Publications, Department of Psychology. 399.

https://digitalcommons.unl.edu/psychfacpub/399

This Article is brought to you for free and open access by the Psychology, Department of at DigitalCommons@University of Nebraska - Lincoln. It has been accepted for inclusion in Faculty Publications, Department of Psychology by an authorized administrator of DigitalCommons@University of Nebraska - Lincoln. 
Published in Professional Psychology: Research and Practice 40:4 (2009), pp. 345-347; doi: 10.1037/a0015734

Copyright ( 2009 American Psychological Association. Used by permission. "This article may not exactly replicate the final version published in the APA journal. It is not the copy of record."

This article is a commentary on B. A. Sharpless \& J. P. Barber, "The Examination for Professional Practice in Psychology (EPPP) in the era of evidence-based practice," Professional Psychology: Research and Practice 40:4 (2009), pp. 333-340.

Submitted November 5, 2008; accepted January 29, 2009.

\title{
How Should the Effectiveness of the EPPP Be Judged?
}

\author{
David DiLillo, University of Nebraska - Lincoln \\ George C. Tremblay, Antioch University, New England \\ Corresponding author - David DiLillo, Department of Psychology, 238 Burnett Hall, \\ University of Nebraska-Lincoln, Lincoln, NE 68588-0308; email ddilillo@unl.edu
}

\begin{abstract}
David DiLillo received his PhD in clinical psychology from Oklahoma State University. He is currently an Associate Professor and Director of Clinical Training at the University of Nebraska-Lincoln. His areas of research include family violence, emotion regulation, and professional training issues. George C. Tremblay received his PhD in clinical psychology from the University at Albany and is currently Professor and Director of Research at Antioch University, New England. His research involves evaluation of human service delivery models in education and health care.
\end{abstract}

\begin{abstract}
We join Brian A. Sharpless and Jacques P. Barber (2009) in calling for strengthening the evidence base supporting the Examination for Professional Practice in Psychology (EPPP), particularly in the areas of criterion and predictive validity. Although 1 clear purpose of the EPPP is to assess core areas of knowledge, materials from the Association of State and Provincial Psychology Boards are less clear as to whether the EPPP is also intended to predict future performance as a psychologist. If the EPPP is expected to protect the public from poorly trained psychologists, then data supporting its use for that purpose are urgently needed. Sharpless and Barber offer suggestions for evaluating the EPPP against this criterion. Although a step in the right direction, these suggestions do not fully satisfy the need for predictive validation. Our greatest difference with Sharpless and Barber concerns their recommendation for abandoning generic licensing in favor of specialty exams tied to subfields. Segmenting licensure in this manner would deviate from the profession's long-standing commitment to broad and general training and would necessarily be accompanied by an undesirably narrowed scope of practice.
\end{abstract}

Keywords: Examination for Professional Practice in Psychology, licensing, psychology licensure, testing procedures, test validity

Sharpless and Barber (2009) present a number of cogent criticisms of the EPPP, and we agree with many of their points. Studies of the predictive and criterion validity of the EPPP are overdue, and the imposition of occupational constraints on the approximately one third of candidates who fail the EPPP is increasingly difficult to justify in the absence of such data. High failure rates do not, of course, constitute a prima facia reason to presume that the exam is not serving its intended purpose; the failure rate for the EPPP is comparable with that for the bar exam (33\% in 2007), which also determines eligibility for a broad, generic license to practice. Still, as Sharpless and Barber have noted, examinees report weak confidence in the validity and fairness of the test (Ryan \& Chan, 1999), which adds to the perception that psychology has constructed unreasonable barriers to entry into the profession (Olvey, Hogg, \& Counts, 2002). Until it can be demonstrated that the EPPP is associated with some relevant performance criterion, the exam and its developers remain vulnerable to charges that it is an arbitrary obstacle serving the professional guild more than the consumer. Perceptions of the EPPP could also be improved by the publication of more data by the Association of State and Provincial Psychology Boards (ASPPB), including pass rates by various demographic variables and individual training programs, which would facilitate evaluation of the exam by outside researchers. Although we join Sharpless and Barber in urging the ASPPB to clarify the purpose of the EPPP and commit to strengthening its psychometric foundation, we perceive some of their recommendations for validity data as somewhat simplistic and their favored solution to the problem as contrary to one of the fundamental tenets of professional psychology training.

The EPPP's validity must rest on a clearly defined purpose of the test. Sharpless and Barber (2009) want to hold the EPPP accountable for demonstrating that the test actually protects the public from incompetent psychologists. The ASPPB's own published materials provide somewhat contradictory statements of the exam's purpose. "Information for Candidates," on the ASPPB Web site, supports the interpretation that it is intended to protect the public, with the statement that, "The EPPP is designed only to protect the public from those who do not have sufficient basic knowledge about psychology to be licensed" (see also http://www.asppb.net/files/public/EPPP_Myth Brochure.pdf). At the same time, the page "Myth vs. Reality," also on the ASPPB's Web site (http://www.asppb. net/files/public/EPPP_Myth_Brochure.pdf), counters with, "There is no suggestion that people who do better 
on the EPPP will be better practitioners." We propose that protection of the public assumes that people who do better on the test will, in fact, be better practitioners; otherwise, what are we protecting the public from? Furthermore, claims by the ASPPB to be protecting the public implicitly make the tenuous assumption that knowledge acquisition automatically translates into responsible and competent professional behavior. Just as demonstrating knowledge of road rules on a written driver's test does not guarantee safe driving, it cannot be assumed that knowledge acquisition demonstrated on the EPPP will result in the application of that knowledge in a professionally responsible manner. For this reason, the ASPPB should explain more explicitly the basis for their claim to be protecting the public.

Sharpless and Barber (2009) suggest three potential ways of validating the EPPP. First, they recommend correlating EPPP scores with supervisors' ratings of applicants on various indicators of performance (relevant knowledge, therapy and assessment skills, etc.). Although this is a reasonable suggestion, it would not address prediction of postlicensure performance. Notably, the ASPPB and other authorities (e.g., Rehm \& Lipkins, 2006) have asserted that, “The EPPP can't be used to predict future performance because people who fail it don't get licensed" (ASPPB fact sheet, "Myth vs. Reality," available at http://www.asppb. net/files/public/EPPP_Myth_Brochure.pdf). If, therefore, we accept that EPPP performance results in only a dichotomous outcome (pass or fail), then the exam will continue to function as an important gatekeeper to the profession that, however, cannot be validated against its major outcome criterion. Sharpless and Barber's second recommendation would address this dilemma by comparing the mean exam scores of psychologists who do and do not get sanctioned by state boards for incompetent or unethical behavior. Incompetence of sufficient proportion to result in sanction is both very rare and likely to involve dimensions of ethical fitness (Kidder, 2003) that the EPPP is not designed to evaluate. Furthermore, we know that prediction of low base rate events is problematic (typically generating a high rate of false positives) and is thus unlikely to be a strong component of validity evidence for the EPPP. Sharpless and Barber also propose that independent experts rate psychologists' competencies as demonstrated in videotaped therapy sessions and that these ratings be correlated with EPPP performance. They cite recent developments in identifying consensus competencies for doctoral-level training (Roberts, Borden, Christiansen, \& Lopez, 2005), and it is possible that reliable coding schemes could be developed to assess these competencies in accordance with Sharpless and Barber's proposal. Whether these competencies could, in turn, be credibly linked to protection of the public is another matter.

Sharpless and Barber emphasize that the EPPP is a "core component of professional licensure" (2009, p. 338), but in focusing their remarks almost exclusively on the EPPP, they have isolated the exam from the broader context of licensure requirements. A novice reader of this article could mistakenly conclude that the assessment of readiness for independent practice (i.e., licensure) rests almost exclusively on the shoulders of the EPPP. For example, the author's assertion that the EPPP is too broad and should focus only on one's intended area of practice does not take into account other licensure requirements, such as supervised clinical experience, which serve that purpose. Thus, Sharpless and Barber place an unusually strong burden on the EPPP to protect the public, without adequately framing it in the context of other licensure requirements. In fact, the EPPP is but one piece of a larger set of evaluative criteria that cumulatively are used to assess readiness for autonomous practice. Other significant components include academic performance in one's training program, quality and quantity of clinical experience, supervisors' evaluations of those experiences, letters of reference, state jurisprudence exams, and oral exams (incidentally, we are unaware of data supporting the validity of these components also in protecting the public, either).

In their final and preferred solution to the challenges of enhancing validity and credibility of the EPPP, Sharpless and Barber (2009) advocate for creation of multiple licensure exams specific to specialty areas of psychology. Although it is not entirely clear how they define specialty, this approach implies that licensees would be tested over a restricted set of competencies corresponding to the intended area of practice (e.g., clinical child, health, geropsychology). Narrowing the relevant content would surely simplify the task of demonstrating criterion validity, but it would also have far-reaching implications for training and practice in the field of professional psychology, which has long valued the notion of "broad and general training." This orientation dates to the Boulder Conference, where participants opted for broad rather than specialized training, and has been reaffirmed through several iterations of the Guidelines and Principles for the Accreditation of Programs in Professional Psychology (American Psychological Association [APA], Commission on Accreditation, 2008) as a cornerstone of training in professional psychology (however, see Roberts, 2006, for an articulation of the case for specialization within subfields). As outlined in the APA Committee (now Commission) on Accreditation's most recent Guidelines and Principles, doctoral programs must ensure that students receive an education in the "breadth of scientific psychology, its history of thought and development, its research methods, and its applications" in the biological, cognitive-affective, and social aspects of behavior (APA Committee on Accreditation, 2005, p. 11 [Domain B, 3a]). The EPPP can be viewed as the primary method of assessing the acquisition of core knowledge mandated by the Commission on Accreditation, at the point of readiness for practice. Moreover, to advocate for a constrained scope of exam content is to advocate for a constrained scope of subsequent professional practice. Although we recognize precedents in other fields (e.g., medicine), we are skeptical that psychologists will be eager to infringe on the freedom we have long enjoyed to engage in diverse and evolving activities under a single license. 


\section{References}

American Psychological Association, Commission on Accreditation. (2008). Guidelines and principles for the accreditation of programs in professional psychology. Washington, DC: APA.

American Psychological Association, Committee on Accreditation. (2005). Guidelines and principles for the accreditation of programs in professional psychology. Washington, DC: APA; (accessed March 17, 2009) http:/ /0-www.apa.org.library.unl. edu/ed/accreditation/G\&P0522.pdf

Kidder, R. (2003). How good people make tough choices: Resolving the dilemmas of ethical living. New York: HarperCollins.

Olvey, C. D., Hogg, A., Counts, W. (2002). Licensure requirements: Have we raised the bar too far?Professional Psychology: Research and Practice, 33, 323-339.

Rehm, L. P., \& Lipkins, R. H. (2006). The examination for professional practice in psychology. In T. J.Vaughn (Ed.), Psychology licensure and certification: What students need to know (pp. 39-53). Washington, DC: APA Books.
Roberts, M. C. (2006). Essential tension: Specialization with broad and general training in psychology. American Psychologist, 61, 862-870.

Roberts, M. C., Borden, K. A., Christiansen, M. D., \& Lopez, S. J. (2005). Fostering a culture shift: Assessment of competence in the education and careers of professional psychologists. Professional Psychology: Research and Practice, 36, 355-361.

Ryan, A. M., \& Chan, D. (1999). Perceptions of the EPPP: How do licensure candidates view the process? Professional Psychology: Research and Practice, 30, 519-530.

Sharpless, B. A., \& Barber, J. P. (2009). The Examination for Professional Practice in Psychology (EPPP) in the era of evidencebased practice. Professional Psychology: Research and Practice, 40, 333-340. 